\title{
Correction to: Morphometric network drainage analysis for railway location: case study of Saudi Railway Company's project
}

\section{Hamad Ahmed Altuwaijri ${ }^{1}$}

Published online: 28 August 2019

(C) Saudi Society for Geosciences 2019

Correction to: Arabian Journal of Geosciences (2019) 12:508 https://doi.org/10.1007/s12517-019-4633-4

The original version of this paper was published with error. The correction in Figure 4 was misinterpreted. Instead of deleting the entire Figure 4b, only the labels "a" and "b" were deleted. Given in this article is the correct figure.

The original article has been corrected.
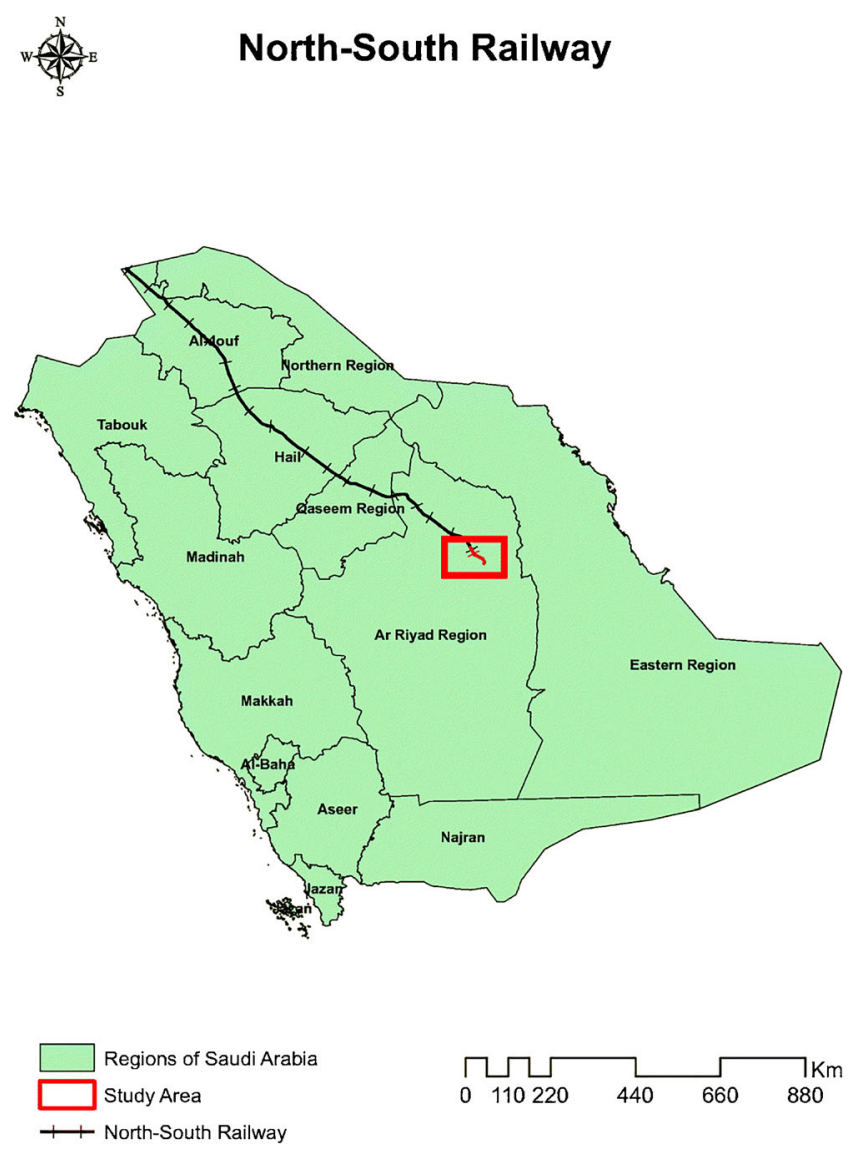

Fig. 4 NSR study area (Source: Researcher, 2018)

The online version of the original article can be found at https://doi.org/ 10.1007/s12517-019-4633-4

Hamad Ahmed Altuwaijri

haaltuwaijri@ksu.edu.sa

1 Department of Geography, King Saud University, Arriyadh 11692, Kingdom of Saudi Arabia 